\title{
Pengaruh Program Gopay Payday Sebagai Customer Relationship Management Terhadap Brand Equity Gojek (PT. Aplikasi Karya Anak Bangsa)
}

\author{
1Viana Eka Wardani, 2 Euis Komalawati, 3Alfirahmi \\ 1,2 \& 3Institut Ilmu Sosial dan Manajemen STIAMI \\ Program Studi Manajemen Komunikasi - Fakultas Ilmu Sosial dan Manajemen \\ email : 1Vianawrdani30@gmail.com,2e_komalawati@yahoo.com, 3alfirahmi.idrus@gmail.com
}

\begin{tabular}{|c|c|}
\hline ARTICLE INFO & ABSTRACT \\
\hline $\begin{array}{l}\text { Keywords: } \\
\text { Customer } \\
\text { Relationship } \\
\text { Management, } \\
\text { Brand Equity }\end{array}$ & $\begin{array}{l}\text { Customer Relationship Management (CRM) is an approach to identifying, } \\
\text { attracting, and improving relationships between companies and customers. Karya } \\
\text { Anak Bangsa Inc. (Gojek) with its application Gopay, gave rise "Gopay Payday" } \\
\text { program as a customer relationship management to decide the brand equity level } \\
\text { of Gopay application users. Brand Equity plays an important role because brand } \\
\text { equity forms the name of the company's image and reputation, even as determining } \\
\text { to make company goals. The purpose of this research analyzes the influence of the } \\
\text { Gopay Payday program as a customer relationship management on Gojek brand } \\
\text { equity (Karya Anak Bangsa Inc.). This research uses quantitative descriptive, and } \\
\text { the method is a purposive sampling technique within } 100 \text { respondents as the } \\
\text { sample. The data analysis technique used SPSS } 25.0 \text { for Windows computer } \\
\text { software tools. The results of this study show that there is a significant influence } \\
\text { on customer relationship management by } 24.2 \% \text { against brand equity. It means } \\
\text { the better the Customer Relationship Management, the Brand Equity of the } \\
\text { company will increase. }\end{array}$ \\
\hline
\end{tabular}

\section{PENDAHULUAN}

Ekonomi global saat ini memasuki perubahan besar, dimulai munculnya revolusi pertama yang ditandai dengan perkembangan perakitan produksi melalui mesin uap hingga saat ini memasuki revolusi industri ke-4, yang menggabungkan antara dunia fisik dan digital. Revolusi Industri 4.0 atau yang sering disebut sebagai era digital telah memasuki segala aspek kehidupan. Teknologi begitu menyentuh pola kehidupan manusia secara personal dari berbagai sudut.

Perkembangan teknologi membawa manfaat bagi manusia, seperti pengatur diet dan olah raga, mengelola investasi, mengatur keuangan, dan lainnya. Teknologi mendorong perusahaan untuk mengikuti perkembangan teknologi, dan menuntut perusahaan untuk mengambil langkah strategis guna terus bertahan dalam menjaga eksistensi.

Salah satu perusahaan, PT. Aplikasi Karya Anak Bangsa (Gojek) merupakan perusahaan Indonesia yang berbasis teknologi, bergerak dalam bidang angkutan melalui jasa transportasi ojek. Perusahaan ini didirikan pada tahun 2010 di Jakarta. Saat ini, layanan Gojek telah tersedia di 50 kota di Indonesia. Selain itu Gojek juga mempunyai layanan pembayaran digital yang bernama Gopay. Gopay tidak hanya digunakan untuk melakukan pembayaran layanan yang tersedia di Gojek saja, tetapi juga dapat melakukan transaksi dengan sejumlah merchant yang bekerja sama dengan Gojek. Selain Gojek dengan layanan pembayaran digital Gopay munculnya beberapa pesaing yang menjalankan bisnis sejenis yaitu OVO, Dana, Saku.id, LinkAja, dsb.

Data yang bersumber dari DailySocial.id pada tahun 2018 menunjukan Gopay menduduki peringkat terpopuler no. 1 dari pesaing lain pada tahun 2017. Dengan banyaknya pesaing tidak menjamin gojek tetap dalam posisi saat ini. Persaingan tersebut mendorong perusahaan untuk meningkatkan produk atau jasa dalam mengelola hubungan dengan pelanggan secara teratur. Pelanggan bukan hanya melakukan transaksional biasa tetapi juga menginginkan yang lebih dari sebuah transaksi seperti pelayanan yang baik. 


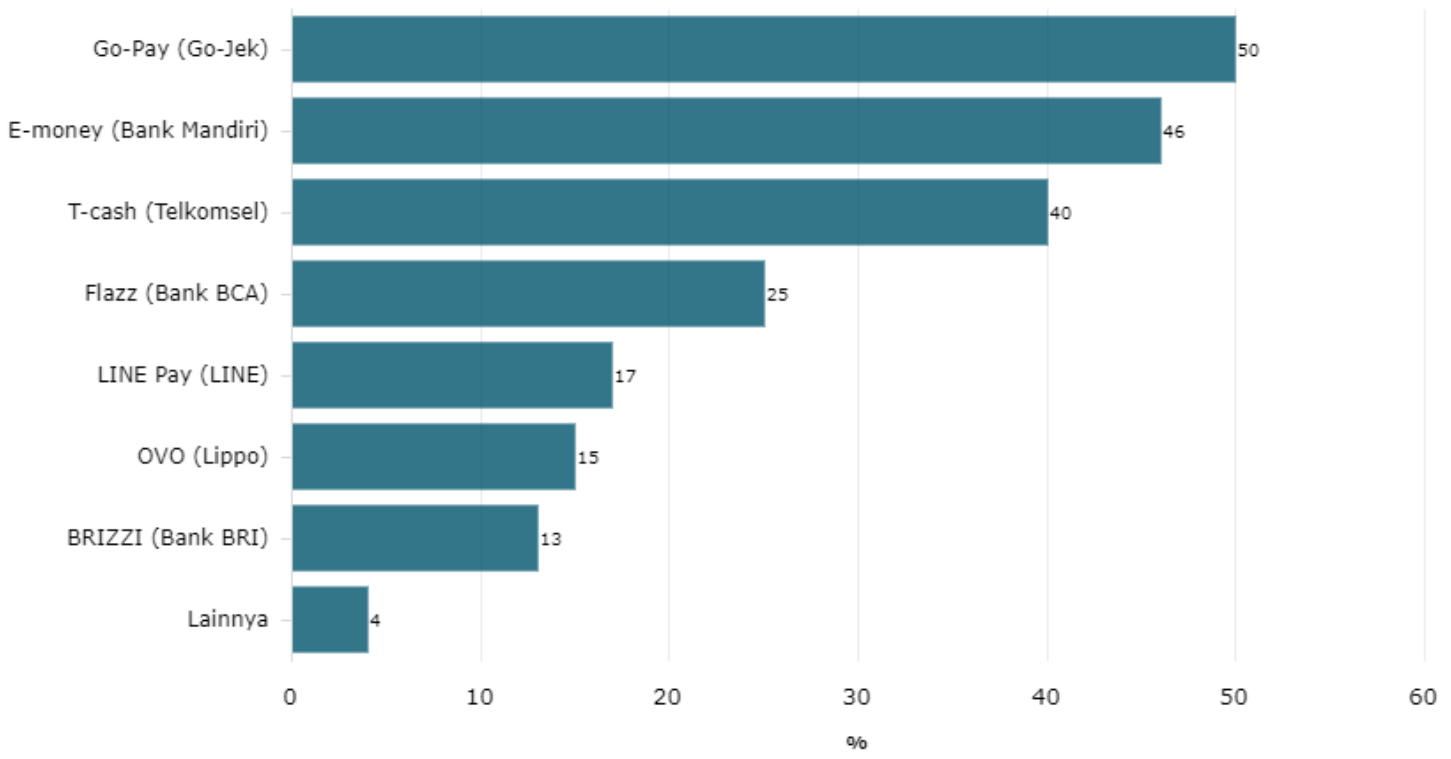

Gambar 1.1 Daftar Uang Elektronik Terpopuler

Sumber: https://katadata.co.id/ (diakses : 11 November 2019)

Dengan kondisi tersebut, peran public relations sangat dibutuhkan dalam menjaga hubungan baik antara semua pihak, dalam hal ini khususnya stakeholder. Seperti yang diketahui pada umumnya stakeholder adalah semua pihak dalam masyarakat, baik individu, komunitas, atau kelompok masyarakat yang memiliki hubungan dan kepentingan suatu organisasi atau perusahaan. Stakeholder memegang peranan penting dalam keberlangsungan suatu perusahaan untuk membantu tercapainya tujuan perusahaan. Apabila hubungan perusahaan dengan stakeholder kurang baik perusahaan akan terkendala dalam melakukan aktifitasnya. Selain itu public relations juga memiliki peran dalam mendukung bauran pemasaran.

Penerapan customer relationship management untuk meningkatkan kemajuan perusahaan dan mempertahankan perusahaan dari persaing lain adalah suatu upaya peran public relations dalam mendukung bauran pemasaran. Upaya tersebut untuk menjaga hubungan dengan stakeholder. Customer atau pelanggan merupakan stakeholder primer karena pelanggan adalah penentu utama pengambilan keputusan dalam pembuatan kebijakan dan program. Customer Relationship Management (CRM) menjadi suatu metode dimana perusahaan dapat terhubung dengan pelanggan, sehingga perusahaan dapat memberikan layanan yang terbaik sesuai dengan kebutuhan pasar.

Dalam peningkatan dan peluasan layanan sebagai bentuk CRM, Gojek bekerja sama dengan banyak merchant popular dari perusahaan groceries hingga kuliner. Untuk memperkuat kerjasama dengan merchant popular dari perusahaan groceries hingga kuliner, Gojek meluncurkan program dengan tagline "Gopay Payday", dimana seluruh pengguna Gojek dapat memanfaat discount yang diselenggarakan pihak merchant melalui metode transaksi digital Gopay. Melalui program CRM, perusahaan meyakini pengguna gopay yang telah ada akan dapat bertumbuh lagi atau justru berpaling karena ketatnya persaingan.

Gojek berusaha memenangkan presepsi positif dari khalayak sehingga brand equity dibutuhkan untuk membangun ekuitas merek perusahaan dimata khalayak agar tidak berpaling menggunakan layanan perusahaan pesaing. Namun realitanya saat ini, berdasarkan pada postingan pada Platform Instagram 31 Oktober 2019, menunjukan ada banyak komplain dari 183 komentar hampir keseluruhan mengeluhkan mengenai cashback yang tidak sesuai dengan promonya (Bersumber Instagram akun @ gopayindonesia). Isu terbesarnya yang menjadi tantangan terberat bagi Gopay ketika semakin banyak merek yang menggunakan alat transaksi digital, juga semakin kuatnya peran pemasaran digital atau pemasaran media sosial. 


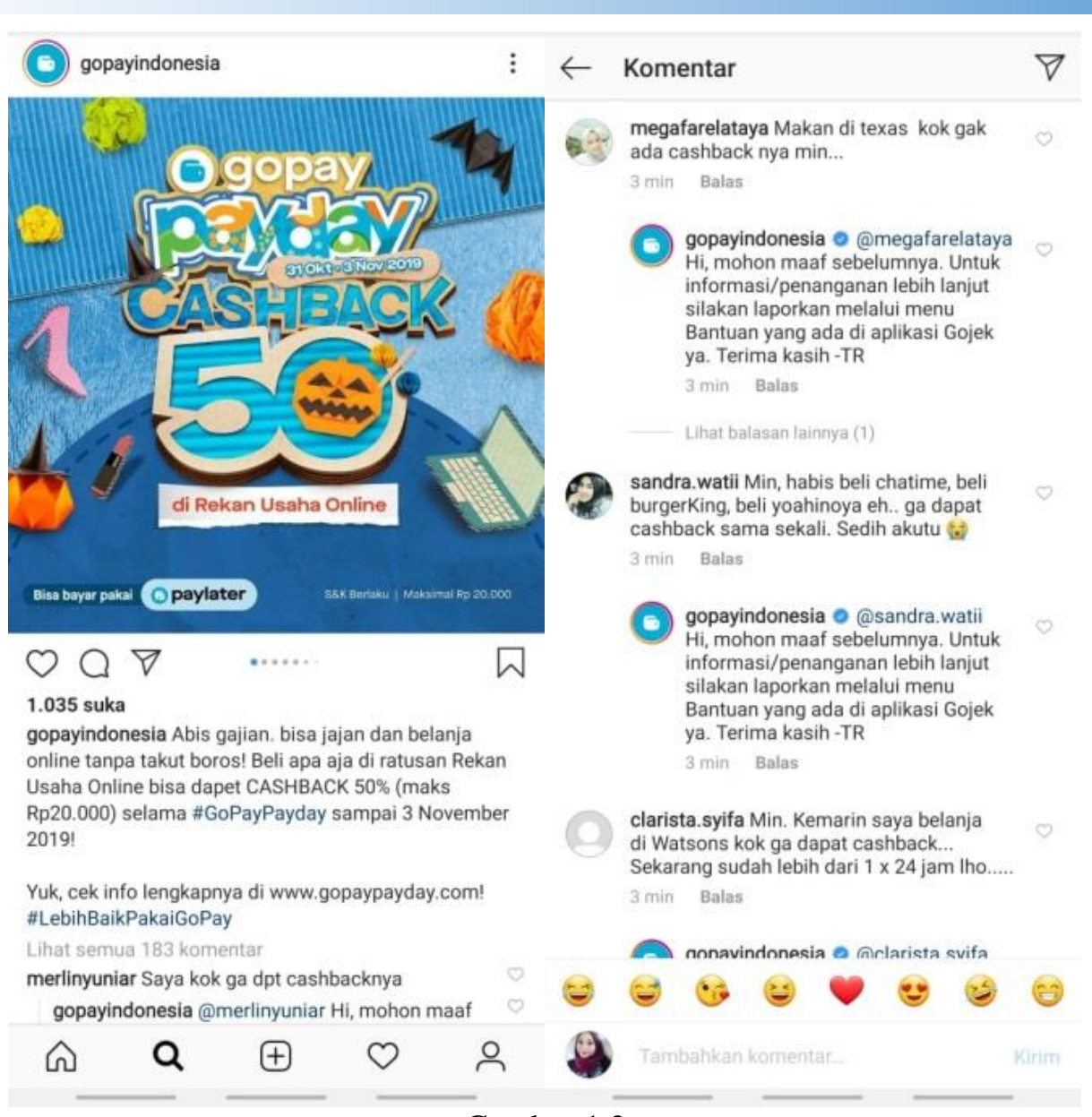

Gambar 1.2

Posting oleh@gopayindonesia dan Keluhan Pengguna

Sumber: Instagram @ gopayindonesia (Diakses 31 November 201)

Dalam penelitian ini, program Gopay Payday sebagai customer relationship management dijadikan sebagai variabel penelitian untuk mengetahui tingkat brand equity. Berbagai macam komplain tersebut berdampak pada pengaruh brand equity Gojek. Semakin banyak calon pelanggan yang belum pernah mencoba bertransaksi melalui Gopay, semakin besar kekhawatiran perusahaan bahwa pelanggan akan berkurang dan beralih ke merek pesaing yang lebih banyak menuai komentar positif di media sosial.

Pemahaman yang baik akan membawa kemajuan yang baik bagi perusahan dan begitu pula sebaliknya, dengan fenomena tersebut, maka perlu diadakan penelitian untuk mengetahui peran Gopay Payday sebagai Customer Relationship Management terhadap Brand Equity Gopay. Pemahaman inilah yang mengacu seorang Public Relations dalam menjalankan tugas dan perannya. Reputasi perusahaan dapat dipengaruhi oleh suatu produk atau merek yang dihasilkan. Brand Equity memegang peran yang sangat penting akan pandangan khalayak terhadap keberadaan sebuah perusahaan, reputasi, ekuitas merk pada dasarnya adalah nama baik perusahaan yang terbentuk atas dasar kepercayaan. Citra dan reputasi perannya membantu, bahkan sebagai yang menentukan dalam pencapaian tujuan perusahaan.

Berdasarkan uraian diatas, yang menjadi tujuan dari penelitian ini adalah untuk menganalisis seberapa besar pengaruh program Gopay Payday sebagai customer relationship management terhadap brand equity Gojek (PT. aplikasi karya anak bangsa).

\section{KERANGKA TEORITIS}

\subsection{Program Customer Relationship Management (CRM)}

Customer Relationship Management (CRM) merupakan suatu pendekatan manajemen yang memungkinkan perusahaan untuk mengidentifikasi, menarik, dan meningkatkan hubungan dengan pelanggan. Oesman (2010) mengatakan CRM merupakan proses mendapatkan, mempertahankan, dan mengembangkan pelanggan yang menguntungkan dan memerlukan suatu fokus yang jelas terhadap atribut suatu jasa yang dapat menghasilkan nilai kepada pelanggan sehingga dapat menghasilkan 
loyalitas. Sedangkan menurut Newell (Imasari, 2011), mengatakan bahwa Customer Relationship Management (CRM) adalah sebuah modifikasi dan pembelajaran perilaku konsumen setiap waktu dari setiap interaksi, perlakuan terhadap pelanggan dan membangun kekuatan antara konsumen dan perusahaan.

Customer Relationship Management (CRM) bertujuan untuk menciptakan pelanggan yang loyal dan berkomitmen terhadap produk dan jasa yang dihasilkan perusahaan (Wildyaksanjani, 2018). Sheth, et.al (2015), mengatakan "we develop a four-stage CRM process framework comprised of the following four sub-processes: a customer relationship formation process; a relationship management and governance process; a relational performance evaluation process, and a CRM evolution or enhancement process".

\subsection{Brand Equity}

Brand Equity adalah nilai tambah yang diberikan oleh produk dan jasa, nilai ini bisa dicerminkan dalam cara konsumen berfikir, merasa dan bertindak terhadap merek, harga, pangsa pasar, dan profitabilitas yang dimiliki perusahaan. Sedangkan menurut David A. Aeker dalam Tjiptono (2011) brand equity adalah serangkaian aset dan kewajiban (liabilities) merek yang terkait dengan sebuah merek, nama, dan simbolnya, yang menambah atau mengurangi nilai yang diberikan sebuah produk atau jasa kepada perusahaan atau pelanggan perusahaan tersebut. Apabila dlihat dari pendekatan berbasis pelanggan brand equity berasal dari perspektif konsumen baik perseorangan maupun organisasi, seperti menurut Kotler dan Keller (2014), customer-based brand equity (ekuitas merek berbasis-pelanggan) adalah pengaruh diferensial yang dimiliki pengetahuan merek atau respon konsumen terhadap pemasaran merek tersebut.

Prinsip dari model Customer-based brand equity bahwa kekuatan perusahaan terletak pada apa yang dilihat, dibaca, didengar, dipelari, dipikirkan, dan dirasakan pelanggan tentang merek sepanjang waktu. Aaker (Surapto, 2014) dalam menyebutkan bahwa brand equity merupakan konsep multidimensi yang terdiri dari brand loyalty, perceived quality, brand association, brand awareness dan asset-aset kepemilikan lainnya.

\section{METODE PENELITIAN}

Pendekatan dalam penelitian ini adalah pendekatan kuantitatif, dengan analisis deskriptif kuantitatif. Deskriptif kuantitatif digunakan untuk mencari pengaruh antar variabel independen dengan variabel dependen (Sugiyono, 2012: 55), pengaruh program Gopay Payday sebagai customer relationship management terhadap brand equity Gojek. Penelitian ini menggunakan dua jenis variabel yaitu variabel independen dan variabel dependen. Variabel bebas atau independen dalam penelitian ini adalah Customer Relationship Management, dengan dimensi continuity marketing programs, one to one marketing programs dan partnering programs. Sedangkan variabel terikat atau dependen dalam penelitian ini adalah Brand Equity, dengan dimensi awereness measures, association measures, perceived quality or leadership measures dan loyalty measures.

Secara umum teknik pengumpulan data dilakukan melalui kuesioner, studi kepustakaan, dan dokumentasi. Populasi dalam penelitian ini adalah pengguna Gojek di kota Bekasi yang berpartisipasi pada program Gopay Payday, dengan sampel sebanyak 100 responden. Analisis data dilakukan melalui Analisis Koefisien Korelasi, Koefisien Determinasi, Analisis Regresi Linear Sederhana, Uji t.

\section{HASIL PENELITIAN DAN DISKUSI}

\subsection{Validitas dan Reliabilitas}

Pengujian validitas diperlukan untuk mengetahui apakah instrumen yang digunakan untuk mencari data primer dalam sebuah penelitian dapat digunakan untuk mengukur apa yang seharusnya terukur. Validitas yang diuji adalah instrumen dari Customer Relationship Management sebagai variabel X dan brand equity sebagai variabel Y dengan menggunakan program SPSS 25.0 for Windows. Jumlah pertanyaan untuk variabel $\mathrm{X}$ sebanyak 10 item dan untuk variabel $\mathrm{Y}$ sebanyak 15 item.

Berdasarkan kuisioner yang diuji pada 30 responden dengan tingkat signifikansi 5\% dan derajat bebas $(\mathrm{df}=\mathrm{n}-2)(30-2=28)$, maka diperoleh nilai $r_{\text {tabel }}$ sebesar 0,361 dari tabel hasil pengujian validitas diketahui bahwa pernyataan-pernyataan yang diajukan kepada responden seluruhnya dinyatakan valid karena memiliki $r$ hitung lebih besar dari $r$ tabel sehingga pernyataan-pernyataan tersebut dapat dijadikan 
alat ukur terhadap konsep yang seharusnya diukur. Pada variabel Customer Relationship semua item valid.

Berdasarkan hasil uji validitas variabel X (Customer Relationship Management) dapat diketahui bahwa nilai tertinggi terdapat pada dimensi Continuity Marketing Programs dengan item pernyataan "Diskon yang diberikan program Gopay Payday membuat saya ingin bertransaksi lebih dari 1 kali" dengan nilai rhitung sebesar 0,783. Nilai terendah juga terdapat pada Continuity Marketing Programs dengan item pernyataan "Saya merasa mudah bertransaksi melalui Gopay pada program Gopay Payday" dengan nilai rhitung sebesar 0,475 . Adapun hasil pengujian koefisien validitas terhadap taraf signifikan tertentu pada tabel di atas, semua nilai rhitung melebihi nilai $r$ tabel $(0,361)$ menunjukkan bahwa adanya koefisien validitas tersebut bukan karena faktor kebetulan.

Hasil uji validitas variabel Y (Brand Equity) dapat diketahui bahwa nilai tertinggi terdapat pada dimensi Perceived quality or leadership measures dengan item pernyataan "Saya memilih Gopay (Gojek) karna memiliki kualitas yang baik dibandingkan merek lain" dengan nilai $\mathrm{r}$ hitung sebesar 0,848 . Nilai terendah terdapat pada dimensi Awereness measures dengan item pernyataan "Gopay (Gojek) menjadi alternatif pilihan untuk melakukan Pembayaran Digital" dengan nilai $r$ hitung sebesar 0,362. Adapun hasil pengujian koefisien validitas terhadap taraf signifikan tertentu pada tabel di atas, semua nilai $r$ hitung melebihi nilai $r$ tabel menunjukkan bahwa adanya koefisien validitas tersebut bukan karena faktor kebetulan.

Hasil pengujian reliabilitas instrumen yang dilakukan dengan bantuan program SPSS 25.0 for Windows diketahui bahwa semua variabel reliabel karena memiliki $\mathrm{r}$ hitung lebih besar dari $\mathrm{r}$ tabel. Hal ini dapat dilihat dalam tabel 1 Hasil Pengujian Reliabilitas berikut ini:

Tabel 1 Hasil Pengujian Reliabilitas

\begin{tabular}{crccc}
\hline No. & Variabel & $\boldsymbol{r}$ hitung & $\boldsymbol{r}_{\text {table }}$ & Keterangan \\
\hline 1 & $\begin{array}{l}\text { Customer } \\
\text { Relationship }\end{array}$ & 0,868 & 0.70 & Reliabel \\
2 & $\begin{array}{l}\text { Management } \\
\text { Brand Equity }\end{array}$ & 0,917 & 0.70 & Reliabel \\
\hline
\end{tabular}

Sumber: Hasil Pengolahan Data 2020 Menggunakan SPSS 25.0 for Windows

Berdasarkan tabel 1, hasil perhitungan menunjukkan bahwa nilai Cronbach's Alpha dari variabel Customer Relationship Management adalah sebesar 0,868 dari 10 butir pertanyaan, dan variabel Brand Equity adalah sebesar 0,917 dari 15 butir pertanyaan. Hasil diatas dapat disimpulkan bahwa kedua variabel yang digunakan dalam penelitian ini adalah reliable karena masing-masing variabel memiliki Cronbach's Alpha $>0,70$ hal ini menunjukkan bahwa setiap butir pertanyaan dalam penelitian ini dapat memperoleh data yang sama dan konsisten apabila diajukan lebih dari satu kali dan akan memiliki jawaban yang relatif sama dengan jawaban responden lain.

\subsection{Analisis Koefisiensi Korelasi}

Hasil pengujian Korelasi dilakukan untuk menguji hipotesis hubungan antara satu variabel independent dengan variabel dependen. Berikut hasil uji korelasi Variabel Customer relationship Brand Equity terhadap Variabel Brand Equity dapat dilihat pada tabel 2.

Tabel 2 Hasil Uji Koefisiensi Korelasi

\begin{tabular}{llrr}
\hline \multicolumn{3}{c}{ Correlations } \\
\hline \multirow{3}{*}{ CRM } & Pearson Correlation & 1 & BE \\
& Sig. (2-tailed) & & $.748^{* *}$ \\
& $\mathrm{~N}$ & $.748^{* * *}$ & .000 \\
& Pearson Correlation & .000 & 100 \\
\hline & Sig. (2-tailed) & 100 & 100 \\
& $\mathrm{~N}$ & & \\
$* *$. Correlation is significant at the 0.01 level (2-tailed).
\end{tabular}

Sumber: Output SPSS 25 for Windows 
Berdasarkan tabel 2, diketahui nilai Korelasi sebesar 0,748 dan nilai signifikasi 0,000. Untuk melakukan interpretasi kekuatan hubungan antara dua variabel bisa dilakukan dengan melihat angka koefisien korelasi melalui tabel 3 berikut :

Tabel 3 Tabel Pedoman Interpretasi Koefisien Korelasi

\begin{tabular}{cc}
\hline Interval Koefisien & Tingkat Hubungan \\
\hline $\mathbf{0 , 0 0}-\mathbf{0 , 1 9 9}$ & Sangat Rendah \\
$\mathbf{0 , 2 0}-\mathbf{0 , 3 9 9}$ & Rendah \\
$\mathbf{0 , 4 0}-\mathbf{0 , 5 9 9}$ & Sedang \\
$\mathbf{0 , 6 0}-\mathbf{0 , 7 9 9}$ & Kuat \\
$\mathbf{0 , 8 0}-\mathbf{1 , 0 0 0}$ & Sangat Kuat \\
\hline
\end{tabular}

Sumber: Sugiyono 2011, 183.

Berdasarkan data diatas, didapatkan hasil bahwa terdapat pengaruh Customer relationship management terhadap Brand Equity dengan korelasi sebesar 0,748.

\subsection{Hasil Analisis Koefisiensi Determinasi}

Koefisien Determinasi digunakan untuk menunjukkan seberapa besar pengaruh antara kedua variabel yang diteliti. Nilai koefisien determinasi dapat dilihat pada tabel 4 pada kolom $R$ Square. Hasil nilai output besar koefisen determinasi (R Square) adalah 0,242 atau 24,2\%. Hal ini menunjukkan bahwa customer relationship management memiliki pengaruh terhadap Brand Equity sebesar 24,2\%, sedangkan $75,8 \%$ dipengaruhi dari faktor lain.

Tabel 4 Hasil Uji Koefisiensi Determinasi

\begin{tabular}{lc|c|c|c}
\hline & \multicolumn{4}{c}{ Adjusted R } \\
Model & $\mathrm{R}$ & $\mathrm{R}$ Square & $\begin{array}{c}\text { Std. Error of the } \\
\text { Square }\end{array}$ \\
\hline $1 \quad .492 \mathrm{a}$ & .242 & & .235 & 7.06822 \\
\hline a. Predictors: & Constant), CRM & & & \\
\hline
\end{tabular}

Sumber: Output SPSS 25.0 for Windows

\subsection{Regresi Linear Sederhana}

Analisis Regresi Linier Sederhana digunakan untuk mengetahui besar pengaruh dari variabel Independen (Customer Relationship Manajemen) terhadap variabel dependen (Brand Equity). Berikut hasil perhitungan koefisien regresi sederhana dengan bantuan program SPSS 25.0 for Windows

\section{Tabel 5 Koefisien Regresi Sederhana}

\section{Coefficientsa}



Sumber: Data olahan Penelitian 2020 melalui

Hasil penghitungan koefisien regresi sederhana diatas memperlihatkan nilai koefisien (Constant) adalah sebesar 30.389 koefisien variabel bebas (CRM) adalah sebesar 0,722. Sehingga diperoleh persamaan regresi $Y=30.389+0,722 X$. Berdasarkan persamaan diketahui nilai konstanta sebesar 30.389. Nilai konstanta ini menyatakan bahwa pada saat variabel Customer Relationship Manajemen dianggap memiliki nilai 0 (nol), maka Brand Equity memiliki nilai 30.389.

Regresi linear sederhana menunjukkan arah hubungan variabel bebas (CRM) dengan variabel terikat (Brand Equity) adalah searah, dimana setiap kenaikan satu satuan variabel CRM akan menyebabkan kenaikan Brand Equity sebesar 0,722. Dengan penjelasan sederhananya adalah koefisien 
bernilai positif artinya terjadi hubungan positif antara Customer Relationship Manajement dengan Brand Equity, semakin baik Customer Relationship Manajement semakin meningkat Brand Equity.

\subsection{Uji parsial (Uji t)}

Hasil pengujian secara keseluruhan memberikan hasil yang signifikan, maka untuk mengetahui variabel bebas yang berpengaruh nyata terhadap Y dapat dilanjutkan pengujian secara parsial.

1) Perumusan Hipotesis

a) $\mathrm{H}_{0}$ : Tidak ada Pengaruh Program Gopay Payday Sebagai Customer Relationship Management Terhadap Brand Equity Gojek

b) $\mathrm{H}_{1}$ : Terdapat Pengaruh Program Gopay Payday Sebagai Customer Relationship Management Terhadap Brand Equity Gojek

2) Penetapan kriteria

Besarnya nilai t tabel untuk taraf signifikan $5 \% \mathrm{db}=98(\mathrm{db}=\mathrm{N}-2$ untuk $\mathrm{N}=100)$ yaitu 1.984

3) Hasil t hitung

Hasil $t$ hitung diperoleh dengan menggunakan SPSS 25.0 for windows pada Tabel IV.39 yaitu sebesar 5.602

4) Pengambilan keputusan

Jika thitung lebih besar dari tabel maka $\mathrm{H}_{1}$ diterima dan $\mathrm{H}_{0}$ ditolak. Dari hasil perhitungan thitung sebesar 5.602 di atas dibandingkan dengan tabel $(\mathrm{db}=98)$ yaitu 1.984 taraf signifikan $5 \%$, jadi $\mathrm{t}$ hitung $>\mathrm{t}$ tabel maka $\mathrm{H}_{1}$ diterima dan $\mathrm{H}_{0}$ di tolak. Dengan kata lain menolak hipotesis nol $\left(\mathrm{H}_{0}\right)$ dan menerima hipotesis alternatif $\left(\mathrm{H}_{1}\right)$ untuk pengujian kedua variabel.

5) Kesimpulan

Sehingga dapat disimpulkan bahwa variabel $X$ terdapat pengaruh yang signifikan terhadap variabel Y. Dari hasil pengujian hipotesis Uji T terbukti bahwa "Terdapat Pengaruh Program Gopay Payday Sebagai Customer Relationship Manajement Terhadap Brand Equity Gojek".

\section{SIMPULAN}

Penelitian ini bertujuan untuk mengetahui besar pengaruh program Gopay Payday sebagai Customer Relationship Management terhadap Brand Equity Gojek. Berdasarkan data yang telah dikumpulkan dan pengujian yang telah dilakukan, maka dapat diambil kesimpulan bahwa terdapat pengaruh program Gopay Payday sebagai Customer Relationship Management terhadap Brand Equity Gojek sebesar 24,2\%. Semakin baik Customer Relationship Management, maka Brand Equity dari perusahaan akan semakin meningkat.

\section{Saran}

Pada hasil penelitian analisis deskriptif ada beberapa hal jawaban para responden yang memiliki nilai dibawah rata-rata terhadap Program Gopay Payday yang dilakukan oleh Gojek, hal tersebut dapat dijadikan rekomendasi dilakukan penelitian selanjutnya serta masukan untuk pihak Gojek sebagai pertimbangan dan evaluasi dalam Program Gopay Payday, antara lain adalah sebagai berikut :

1. Perusahaan harus lebih baik dalam merespon dan memberikan feedback terhadap keluhan

2. Perusahaan harus mengevaluasi dan menambah merchant yang tergabung untuk dapat memenuhi kebutuhan pengguna secara lengkap

3. Perusahaan harus mengevaluasi kembali pelayanan dan kualitas merchant yang bergabung

4. Perusahaan harus memevaluasi kembali terhadap pengampaian informasi promosi terhadap merchant yang tergabung

5. Perusahaan harus melihat dan mempelajari penawaran promosi pesaing lain untuk dapat melihat kekurangan dan kelebihan dalam kebutuhan konsumen sehingga Brand Equity dapat lebih Kuat. 


\section{DAFTAR PUSTAKA}

[1] Imasari, Kartika \& Nursalin, Kezia Kurniawati. Pengaruh Customer Relationship Management terhadap Loyalitas Pelanggan pada PT BCA Tbk. Jurnal Fakultas Ekonomi Universitas Kristen Maranatha Vol. 10, No. 3 (2011). (imasari \& Imasari, 2011)

[2] Kotler, Philip dan G. Amstrong. 2014. Principles of Marketing: Global Edition. 15th. England: Pearson

[3] Oesman, Yevis Marty. 2010. Sukses Mengelola Marketing Mix, CRM, Customer Value, dan Customer Dependency. Bandung: Alfa (Sheth, 2015)beta

[4] Sheth, Jagdish N., et al. The conceptual foundations of relationship marketing: Review and synthesis. Journal of Economic Sociology. Vol.16 No. 2 (2015)

[5] Sugiyono. 2012. Metode Penelitian Bisnis. Bandung: Alfabeta.

[6] Sugiyono. 2011. Metode Penelitian Kuantitatif, Kualitatif dan R\&D. Bandung: Afabeta

[7] Surapto, Deni. Analisa Brand Equity Universitas Terbuka (UT) Di UPBJJ-UT Bogor Dengan Menggunakan Model Brand Equity Ten. Jurnal Organisasi dan Manajemen Vol. 10, No. 1 (2014)

[8] Tjiptono, Fandy. (2011). Strategi Pemasaran. Edisi 3. Yogyakarta: Andi.

[9] Wildyaksanjani, Janiar Puspa \& Dadang Sugiana. Strategi Customer Relationship Management (CRM) PT Angkasa Pura II (Persero). Jurnal Kajian Komunikasi Vol. 6, No. 1 (2018).

[10]https://katadata.co.id/ (diakses : 11 November 2019) 